\title{
Comprehensive geriatric assessment prediction of postoperative complications in gastrointestinal cancer patients: a meta-analysis
}

This article was published in the following Dove Press journal:

Clinical Interventions in Aging

\author{
Dan-dan Xue ${ }^{1,2}$ \\ Yun Cheng' \\ Mei Wu ${ }^{2}$ \\ Yan Zhang ${ }^{3}$
}

'Nursing Department, Huadong Hospital Affiliated to Fudan University, Shanghai, People's Republic of China; ${ }^{2}$ School of Nursing, Fudan University, Shanghai, People's Republic of China; ${ }^{3}$ Department of General Surgery, Huadong Hospital Affiliated to Fudan University, Shanghai, People's Republic of China
Correspondence: Yun Cheng Nursing Department, Huadong Hospital Affiliated to Fudan University, No. 22I West Yan'an Road, Jing'an District, Shanghai, 200040, People's Republic of China

Tel +86 2l 62490575

Fax +86 21 6248498

Email yun91@hotmail.com
Background: Gastrointestinal cancer is an age-associated disease, and geriatric patients are mostly likely to suffer from postoperative complications. Some studies indicated that comprehensive geriatric assessment (CGA) could predict postoperative complications in gastrointestinal cancer patients. However, the evidence is mixed.

Objective: This study aimed to conduct a meta-analysis to identify the effectiveness of CGA for predicting postoperative complications in gastrointestinal cancer patients.

Methods: The Joanna Briggs Institute Library, Cochrane Library, PubMed, Embase, Web of Science, CINAHL Complete and four Chinese databases were searched for studies published up to March 2017. Two reviewers independently screened literature, extracted data and assessed the quality of included studies. RevMan5.3 was used for meta-analysis or only descriptive analysis.

Results: Six studies were included, with 1,037 participants in total. In all, 13 components of CGA were identified, among which comorbidity (Charlson Comorbidity Index $[\mathrm{CCI}] \geq 3$; odds ratio $[\mathrm{OR}]=1.31,95 \% \mathrm{CI}[1.06,1.63], P=0.01)$, polypharmacy $(\geq 5 \mathrm{drugs} / \mathrm{day} ; \mathrm{OR}=1.30$, $95 \% \mathrm{CI}[1.04,1.61], P=0.02)$ and activities of daily living (ADL) dependency (OR=1.69, 95\% CI $[1.20,2.38], P=0.003)$ were proven relevant to the prediction of postoperative complications. No conclusive relationship was established between instrumental activities of daily living (IADL) dependency $(\mathrm{OR}=1.18,95 \% \mathrm{CI}[0.73,1.91], P=0.51)$, Mini-Mental State Examination (MMSE; $\mathrm{OR}=1.13,95 \% \mathrm{CI}[0.91,1.41], P=0.27)$, potential malnutrition $(\mathrm{OR}=1.07,95 \% \mathrm{CI}[0.87,1.31]$, $P=0.54)$, malnutrition ( $\mathrm{OR}=1.26,95 \%$ CI $[0.80,1.99], P=0.32)$, Geriatric Depression Scale (GDS; OR=1.18, 95\% CI [0.90, 1.55], $P=0.24$ ) and postoperative complications.

Conclusion: Comorbidity (CCI $\geq 3$ ), polypharmacy ( $\geq 5$ drugs/day) and ADL dependency were predictive factors for postoperative complications in gastrointestinal cancer patients; the results of other geriatric instruments were not conclusive, pointing to insufficient studies and requirement of more original investigations.

Keywords: comprehensive geriatric assessment, gastrointestinal cancer, complication, metaanalysis

\section{Introduction}

Gastrointestinal cancer is one of the world's most prevalent malignancies, with a high incidence (stomach and colorectal cancers ranking fifth and third, respectively) and mortality rate (stomach and colorectal cancer ranking third and fourth, respectively). ${ }^{1}$ In the United States in 2017, an estimated 135,430 individuals newly diagnosed with colorectal cancer and 50,260 deaths from the disease. ${ }^{2}$ In China alone, there was a sharp increase in the standardized incidence of colorectal cancer (from 12.15/100,000 to 20.27/100,000) and deaths from stomach 
cancer (from 2.821 million to 3.178 million) from 1990 to 2013. ${ }^{3,4}$ Considering challenges arising with aging societies, study showed that nearly $60 \%$ of newly diagnosed colorectal cancer occurs in people older than 65 years. ${ }^{2}$

Age probably is an independent risk factor for complications, but age alone does not exclude surgery as a treatment option. ${ }^{5}$ With the advances in surgical and anesthetic techniques, the extended life expectancy of the elderly, patients aged $\geq 65$ years with cancer tend to surgical treatment and the surgical resection rate is high even in advanced age. ${ }^{6}$ However, geriatric patients are most likely to be in poor health state due to combinations of physiological ageassociated decline, multiple illnesses, psychological alterations and geriatric syndromes. When surgery is performed, these vulnerabilities may lead to compromised postoperative outcomes, including increased incidence of complications, extended hospitalization, progressive functional decline and death. ${ }^{7,8}$ Therefore, thorough assessment is critical for geriatric patients being considered for surgery to recognize risk factors and take individualized care. ${ }^{7}$

Comprehensive geriatric assessment (CGA) is a multidimensional evaluation of general health condition based on validated scales and tests producing an inventory of health problems designed by geriatricians. ${ }^{9} \mathrm{CGA}$ is different from those traditional evaluation treatments as it is a multidimensional, interdisciplinary and comprehensive diagnostic process. It provides systematic structured assessment of patient's overall health status including physical function, nutrition, mental or psychological status, functional status (FS), social support and geriatric syndromes. CGA is helpful to identify deficits that are not routinely captured in a standard history and physical examination, determine risk stratification, make surgical decisions and guide targeted geriatric interventions in response to CGA impairments and thus optimizes preoperative health state and improves postoperative outcomes. ${ }^{10-12}$

Recently, some studies indicated that components of CGA could predict postoperative complications in gastrointestinal cancer patients, but empirical evidence is mixed. ${ }^{13,14}$ Therefore, this study aimed to conduct a meta-analysis to identify the effectiveness of CGA for predicting postoperative complications in gastrointestinal cancer patients, in order to provide scientifically substantiated suggestions for perioperative clinical care.

\section{Methods}

\section{Inclusion and exclusion criteria}

Studies both in English and Chinese with the following criteria were included: 1) types of participants: patients aged $\geq 65$ years undergoing elective surgery for gastrointestinal cancer; 2) types of studies: observational studies including case-control and cohort studies reporting factors (single factor excluded) that included CGA for predicting postoperative complications and 3) types of outcome measures: postoperative complications occurring within 30 or 90 days after surgery.

Studies were excluded if valid data information could not be extracted or only the abstract (full text unavailable) was available.

\section{Search strategy}

The following databases were used to search: Cochrane Library, Joanna Briggs Institute Library, PubMed, Embase (via Ovid), Web of Science, CINAHL Complete, China National Knowledge Infrastructure (CNKI), Chinese Biomedical Literature Database (CBM), Wanfang and VIP database. The search was limited to March 2017. We developed detailed search strategies (Supplementary material) based on the MeSH and text word strategy. The search terms were: ("comprehensive geriatric assessment" OR "CGA") AND ("stomach" OR "gastric" OR "colon" OR "rectal” OR “colorectal" OR "gastrointestinal") AND (“cancer" OR "tumor" OR “neoplasms" OR “carcinoma”). Two researchers, Xue and $\mathrm{Wu}$, independently abstracted data from the search methods mentioned earlier including four steps: 1) retrieved the Cochrane Library and the Joanna Briggs Institute (JBI) Library for related systematic reviews or meta-analyses; 2) the original research of PubMed, Embase, Web of Science, CNKI, CBM, Wanfang and other Chinese and English databases were searched, and the obtained literature titles, abstracts, keywords and MeSH words were analyzed to further determine the keywords of literature retrieval; 3) used all relevant keywords and MeSH words for further search, and if the abstract met the inclusion criteria, read the full text and 4) further retrieved the references of the related research.

\section{Data extraction}

Full article review was conducted for all included studies. Two researchers extracted the study data including first author's last name, country, design of study, duration of study, cancer type, sample size, mean age, outcome and main conclusion (Table 1).

\section{Quality assessment}

The Newcastle-Ottawa Scale (NOS) was used for quality assessment. ${ }^{15}$ The scale evaluates each study on eight items grouped into three categories including the study population selection, comparability and outcome. A study can be 
Table I Characteristics of the included studies

\begin{tabular}{|c|c|c|c|c|c|c|c|c|}
\hline \multirow{2}{*}{$\begin{array}{l}\text { Study } \\
\text { (country) }\end{array}$} & \multirow{2}{*}{$\begin{array}{l}\text { Design } \\
\text { (duration } \\
\text { of study) }\end{array}$} & \multirow[t]{2}{*}{ Cancer type } & \multirow{2}{*}{$\begin{array}{l}\text { Sample } \\
\text { size }\end{array}$} & \multirow{2}{*}{$\begin{array}{l}\text { Mean } \\
\text { age } \\
\text { (years) }\end{array}$} & \multicolumn{3}{|l|}{ Outcome } & \multirow[t]{2}{*}{ Main conclusion } \\
\hline & & & & & $\begin{array}{l}30 \text {-day } \\
\text { postoperative } \\
\text { any } \\
\text { complications } \\
(n, \%)\end{array}$ & $\begin{array}{l}\text { 30-day } \\
\text { postoperative } \\
\text { major } \\
\text { complications } \\
(\mathrm{n}, \%)\end{array}$ & $\begin{array}{l}\text { 90-day } \\
\text { postoperative } \\
\text { major } \\
\text { complications } \\
(\mathrm{n}, \%)\end{array}$ & \\
\hline $\begin{array}{l}\text { Kenig et al }{ }^{14} \\
\text { (Poland) }\end{array}$ & $\begin{array}{l}\text { Cohort study } \\
(2013-2014)\end{array}$ & $\begin{array}{l}\text { Colorectal } \\
\text { cancer } 66.6 \% \text {, } \\
\text { gastric cancer } \\
10.7 \% \text {, others } \\
22.7 \%\end{array}$ & 75 & 73 & $38,50.7$ & $20,26.7$ & - & $\begin{array}{l}\text { TUGT and } \\
\text { MOS-SSS were } \\
\text { predictive factors } \\
\text { of postoperative } \\
\text { morbidity (both } \\
\text { any and major } \\
\text { complications); } \\
\text { polypharmacy was } \\
\text { an independent risk } \\
\text { factor of 30-day } \\
\text { postoperative } \\
\text { major } \\
\text { complications }\end{array}$ \\
\hline $\begin{array}{l}\text { Tan et al }{ }^{18} \\
\text { (Singapore) }\end{array}$ & $\begin{array}{l}\text { Cohort study } \\
(2008-2010)\end{array}$ & $\begin{array}{l}\text { Colorectal } \\
\text { cancer }\end{array}$ & 83 & 81.5 & - & $22,26.5$ & - & $\begin{array}{l}\text { Patients with } \\
\text { frailty had a } \\
\text { significant four } \\
\text { times higher risk of } \\
\text { developing } 30 \text {-day } \\
\text { postoperative major } \\
\text { complications }\end{array}$ \\
\hline $\begin{array}{l}\text { Pujara } \\
\text { et al }{ }^{19} \\
\text { (USA) }\end{array}$ & $\begin{array}{l}\text { Cohort study } \\
(2005-2014)\end{array}$ & $\begin{array}{l}\text { Gastric and } \\
\text { gastroesophageal } \\
\text { cancers }\end{array}$ & 279 & 64 & - & - & 67,24 & $\begin{array}{l}\text { Pain scale } \\
\text { score }>0, \geq 10 \% \\
\text { weight loss and } \\
\text { polypharmacy were } \\
\text { independently } \\
\text { associated } \\
\text { with } 90 \text {-day } \\
\text { postoperative major } \\
\text { morbidity }\end{array}$ \\
\hline $\begin{array}{l}\text { Lee et } \mathrm{al}^{13} \\
\text { (Korea) }\end{array}$ & $\begin{array}{l}\text { Cohort study } \\
(2009-2014)\end{array}$ & $\begin{array}{l}\text { Colon tumor } \\
62.5 \% \text {, rectum } \\
\text { tumor } 37.5 \%\end{array}$ & 240 & 76.7 & $183,76.3$ & $99,41.3$ & - & $\begin{array}{l}\text { A score of } \geq 3 \text { for } \\
\text { comorbidities and } \\
\text { a high ADL score } \\
\text { were significantly } \\
\text { and independently } \\
\text { associated with } \\
\text { a risk of major } \\
\text { complications }\end{array}$ \\
\hline $\begin{array}{l}\text { Kristjansson } \\
\text { et a }{ }^{17} \\
\text { (Norway) }\end{array}$ & $\begin{array}{l}\text { Cohort study } \\
(2006-2008)\end{array}$ & $\begin{array}{l}\text { Colon tumor } \\
71 \% \text {, rectum } \\
\text { tumor } 29 \%\end{array}$ & 182 & 80 & - & - & - & $\begin{array}{l}\text { Severe comorbidity } \\
\text { was the only } \\
\text { CGA element } \\
\text { predicting major } \\
\text { complications; IADL } \\
\text { dependency and } \\
\text { depression were } \\
\text { predictors of any } \\
\text { complications }\end{array}$ \\
\hline $\begin{array}{l}\text { Kristjansson } \\
\text { et a }{ }^{16} \\
\text { (Norway) }\end{array}$ & $\begin{array}{l}\text { Cohort study } \\
(2006-2008)\end{array}$ & $\begin{array}{l}\text { Colon tumor } \\
71 \% \text {, rectum } \\
\text { tumor } 29 \%\end{array}$ & 178 & 79.6 & $107,60.1$ & $83,46.6$ & - & $\begin{array}{l}\text { Frailty was } \\
\text { significantly } \\
\text { associated } \\
\text { with both any } \\
\text { complications and } \\
\text { major complications }\end{array}$ \\
\hline
\end{tabular}

Abbreviations: TUGT, Timed Up and Go Test; MOS-SSS, Medical Outcomes Study Social Support Scale; ADL, activities of daily living; CGA, comprehensive geriatric assessment; IADL, instrumental activities of daily living. 
awarded one star for each item within the study population selection and outcome categories and two stars for comparability. One star refers to a score of 1 , and studies with a total score of $\geq 7$ were considered as high-quality studies. Both reviewers independently assessed the quality of the included studies. If there was any divergence, the third reviewer (Cheng) was sought to reach a consensus.

\section{Statistical analysis}

First, the existence of clinical and methodological heterogeneity between the studies was judged. Subgroup analysis was conducted where there was clinical heterogeneity and methodological heterogeneity on the basis of the factors leading to heterogeneity or only descriptive analysis. In the absence of clinical heterogeneity and methodological heterogeneity and on meeting the quality of the criteria, meta-analysis was performed using RevMan 5.3 software. The statistical heterogeneity between studies was determined based on the chi-square test. The fixed-effects model was used when heterogeneity was not significant ( $P \geq 0.1, I^{2}<50 \%$ ), otherwise the random-effects model was used.

\section{Results Study selection}

As shown in Figure 1, the searches identified 1,280 potentially relevant studies. In all, 242 articles were excluded due to duplication. After screening the titles and abstracts, we excluded 1,016 studies. The 22 full-text studies were reviewed, and 16 articles were excluded because there were no geriatric patients with gastrointestinal cancer as subjects, they were not observational studies and they did not report postoperative complications as outcome or preoperative CGA for predicting postoperative complications. A total of four studies were excluded due to having an abstract only or full text unavailable. Two reports on the same study were included in the meta-analysis (but the reported factors focused on were different): one report determined frailty based on CGA results and explored the relationship between frailty and postoperative complications ${ }^{16}$ and another report analyzed the association between components of CGA and postoperative complications. ${ }^{17}$ Finally, six studies with 1,037 participants were included in the final analysis.

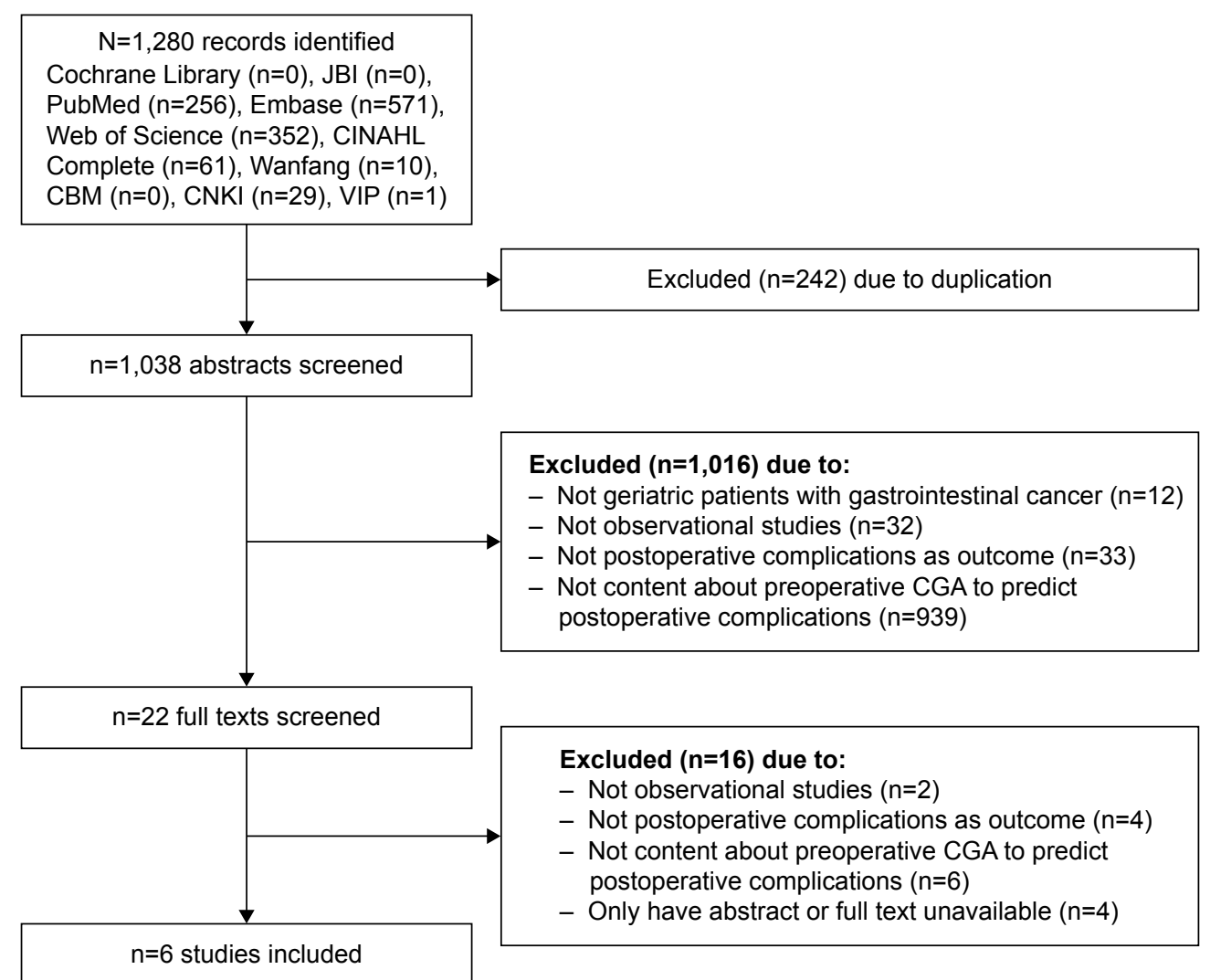

Figure I Flowchart of study search and selection process.

Abbreviations: JBI, Joanna Briggs Institute; CBM, Chinese Biomedical Literature Database; CNKI, China National Knowledge Infrastructure; CGA, comprehensive geriatric assessment. 


\section{Characteristics of studies}

The characteristics of the included six studies are presented in Table 1. They were published between 2010 and 2016 and conducted in five countries, including Poland, Singapore, USA, Korea and Norway. The sample size ranged from 75 to 279 participants, and the mean age varied from 64 to 81.5 years. The incidence of postoperative complications was from $24 \%$ to $76.3 \%$. In all, 13 components of CGA were assessed in the six studies (Table 2). Six components of CGA including comorbidity, polypharmacy, FS, cognition, depression and nutritional status were evaluated in four or more than four studies. Frailty was assessed in two studies, and other six components including falls, pain, physical activity, fatigue, social support and delirium were assessed only in one study. Different assessment tools were used for nutrition (four methods), comorbidity, FS, cognition (three methods) and frailty (two methods). Depression, falls, pain, physical activity, fatigue, social support and delirium were evaluated by the same measure.

\section{Methodological quality}

Results of NOS assessment are shown in Table 3, which identified four cohort studies ${ }^{14,16-18}$ with a high quality. Description of the ascertainment of exposure was missing in four studies. ${ }^{14,16,18,19}$ Two studies ${ }^{13,19}$ failed to adjust the risk factors, and the assessment of outcome was insufficient in three studies. ${ }^{13,18,19}$

\section{0-day postoperative any complications}

Postoperative any complications means any event requiring treatment measures that were not routinely applied in the postoperative period and were assessed in three of the six studies. ${ }^{14,16,17}$ Elements of CGA including Timed Up and Go Test (TUGT), Medical Outcomes Study Social Support Scale (MOS-SSS), instrumental activities of daily living (IADL) dependency and depression were predictive factors of 30-day postoperative any complications. ${ }^{14,17}$ Additionally, frailty was significant with 30 -day postoperative any complications. ${ }^{16}$

\section{0-day postoperative major complications}

Postoperative major complications referred to complications of grade 2 or higher according to the Clavien-Dindo classification, either life threatening or requiring significant deviation from standard treatment. ${ }^{18,20}$ The 30 -day postoperative major complications were assessed in five of the six studies, and all the five studies analyzed the association

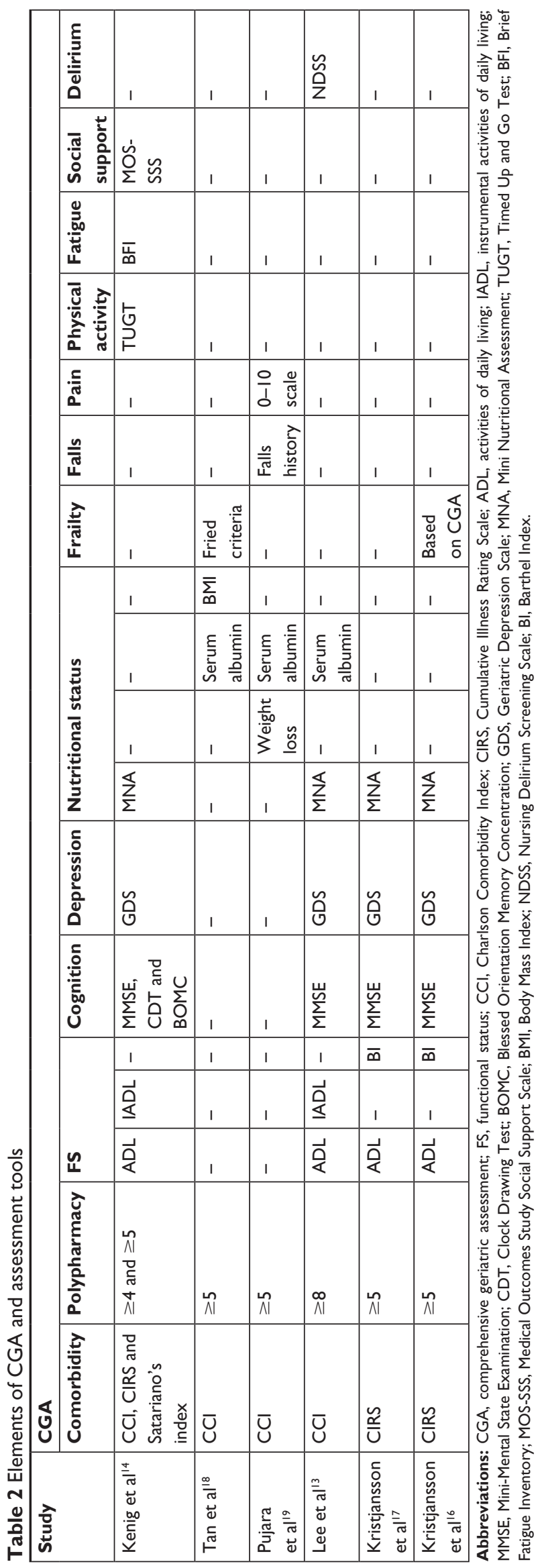




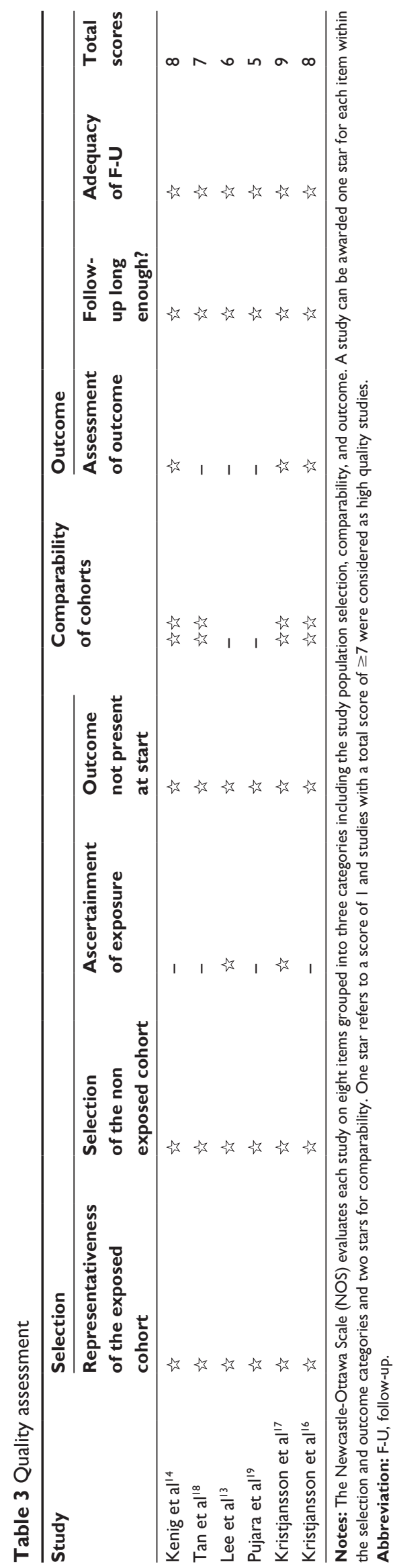

between elements of preoperative CGA and 30-day postoperative major complications. ${ }^{11,12,14-16}$

\section{Comorbidity}

Comorbidity was assessed in all six studies ${ }^{13,14,16-19}$ using three different tools, including Charlson Comorbidity Index (CCI), Cumulative Illness Rating Scale (CIRS) and Satario's Index. Four studies reported the relationship between comorbidity and 30-day postoperative major complications. ${ }^{13,14,17,18}$ One study showed that severe comorbidity was an independent predictor of major complications. ${ }^{17}$ In this study, comorbidities were classified according to CIRS scores, and severe comorbidities were defined as three grade 3 comorbidities or any grade 4 comorbidity. Two studies analyzed the association between a score of $\geq 3$ for $\mathrm{CCI}$ and 30-day postoperative major complications. ${ }^{13,14}$ One prospective study analyzed the predictive value of a score of $>5$ for $\mathrm{CCI}$ for the development of 30 -day postoperative major complications. ${ }^{18}$ There was no heterogeneity among the three studies $(P=0.62$, $I^{2}=0 \%$ ). In the fixed-effects model, CCI $\geq 3$ was identified as the predictive factor of 30-day postoperative major complications (odds ratio [OR] $=1.31,95 \%$ CI $[1.06,1.63]$, $P=0.01$; Figure 2).

\section{Polypharmacy}

Polypharmacy was assessed in five studies. ${ }^{13,14,16-18}$ Three studies identified the association between polypharmacy and 30-day postoperative major complications. ${ }^{13,14,17}$ Of these studies, one defined polypharmacy as 4 or 5 drugs/day and showed the association between $>4$ drugs/day, $>5$ drugs/day and 30-day postoperative major complications. ${ }^{14}$ One study defined it as more than or equal to five daily medications. ${ }^{17}$ Lee et $\mathrm{a}^{13}$ defined polypharmacy as the regular use of eight or more drugs. There was no heterogeneity among the three studies $\left(P=0.16, I^{2}=46 \%\right)$. In the fixed-effects model, $\geq 5$ drugs/day was identified as the predictive factor of 30-day postoperative major complications ( $\mathrm{OR}=1.30,95 \%$ CI [1.04, 1.61], $P=0.02$; Figure 3).

\section{FS}

FS was assessed in four of the six studies, ${ }^{13,14,16,17}$ using tools that included ADL, IADL and Barthel Index (BI). Three studies analyzed the association between FS and 30-day postoperative major complications. ${ }^{13,14,17}$ One study explained the relationship between $\mathrm{BI}$ and postoperative complications and revealed that BI was not a predictive factor of 30-day postoperative major complications. ${ }^{17}$ Two studies analyzed the relationship between ADL dependency, ${ }^{13,17}$ IADL dependency ${ }^{13,14}$ and 30-day postoperative major complications. Subgroup 


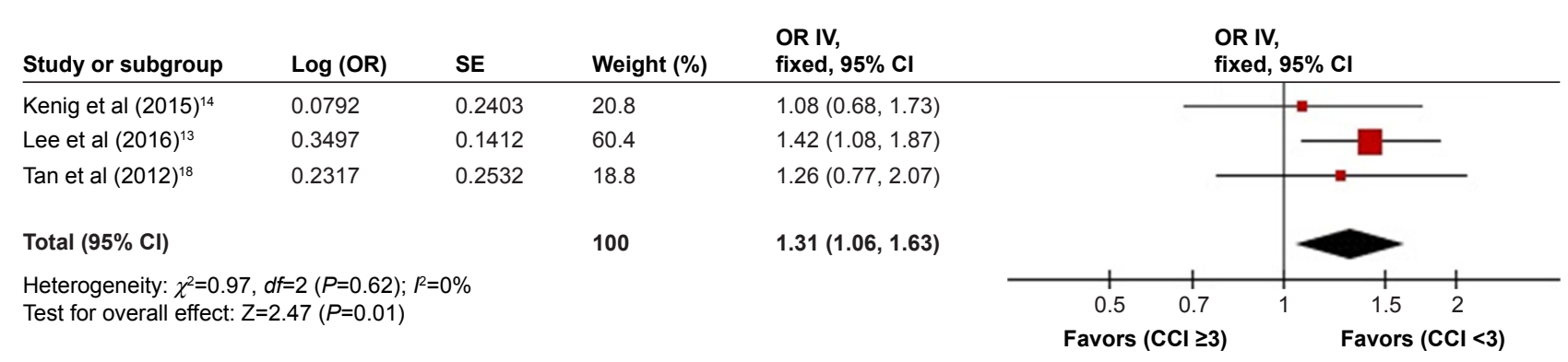

Figure 2 Effects of comorbidity on 30-day postoperative major complications.

Abbreviations: OR, odds ratio; SE, standard error; IV, inverse variance; $\mathrm{CCl}$, Charlson Comorbidity Index.

analysis was conducted based on the evaluation tools; there was no heterogeneity among the three studies $(P=0.34$, $I^{2}=11 \%$ ). In the fixed-effects model, ADL dependency was identified as a predictive factor of 30-day postoperative major complications ( $\mathrm{OR}=1.69,95 \% \mathrm{CI}[1.20,2.38], P=0.003)$; the prediction of IADL dependency was inconclusive $(\mathrm{OR}=1.18$, 95\% CI [0.73, 1.91], $P=0.51$; Figure 4).

\section{Cognition}

Cognition was assessed in four of the five studies. ${ }^{13,14,16,17}$ Three studies ${ }^{13,16,17}$ used Mini-Mental State Examination (MMSE) to evaluate cognition, and one ${ }^{14}$ study used three measures, including the MMSE, Blessed Orientation Memory Concentration (BOMC) Test and Clock Drawing Test (CDT). Three studies ${ }^{13,14,17}$ analyzed the association between MMSE cognitive impairment and 30-day postoperative major complications, and there was no heterogeneity among the three studies $\left(P=0.34, I^{2}=8 \%\right)$. In the fixed-effects model, the prediction of MMSE cognitive impairment for 30-day postoperative major complications was inconclusive $(\mathrm{OR}=1.13$, 95\% CI [0.91, 1.41], $P=0.27$; Figure 5).

\section{Nutrition}

Nutrition was assessed in all five studies; ${ }^{13,14,16-18}$ the methods included Mini Nutritional Assessment (MNA), the level of serum albumin, weight loss and body mass index (BMI). One study analyzed the relationship between MNA malnutrition and potential malnutrition and 30-day postoperative major complications. ${ }^{14}$ Two studies analyzed the association between MNA malnutrition, potential malnutrition and 30-day postoperative major complications. ${ }^{13,17}$ Subgroup analysis was conducted based on the score of MNA; there were no heterogeneity among the two studies $(P=0.15$, $\left.I^{2}=44 \%\right)$. In the fixed-effects model, the prediction of MNA malnutrition ( $\mathrm{OR}=1.26,95 \% \mathrm{CI}[0.80,1.99], P=0.32)$, MNA potential malnutrition $(\mathrm{OR}=1.07,95 \%$ CI $[0.87,1.31]$, $P=0.54$ ) and 30-day postoperative major complications was inconclusive (Figure 6).

\section{Depression}

Depression was assessed in four of the five studies, and Geriatric Depression Scale (GDS) was used to evaluate it. ${ }^{13,14,16,17}$ Three studies analyzed the association between GDS depression and 30-day postoperative major complications. ${ }^{13,14,17}$ There were no heterogeneity among the three studies ( $P=0.76, I^{2}=0 \%$ ). In the fixed-effects model, the prediction of GDS depression for 30-day postoperative major complications was inconclusive (OR=1.18, 95\% CI $[0.90,1.55]$, $P=0.24$; Figure 7).

Frailty

Frailty was assessed in two of the five studies. ${ }^{16,18}$ One study categorized patients into three groups including fit, intermediate and frail based on the preoperative CGA

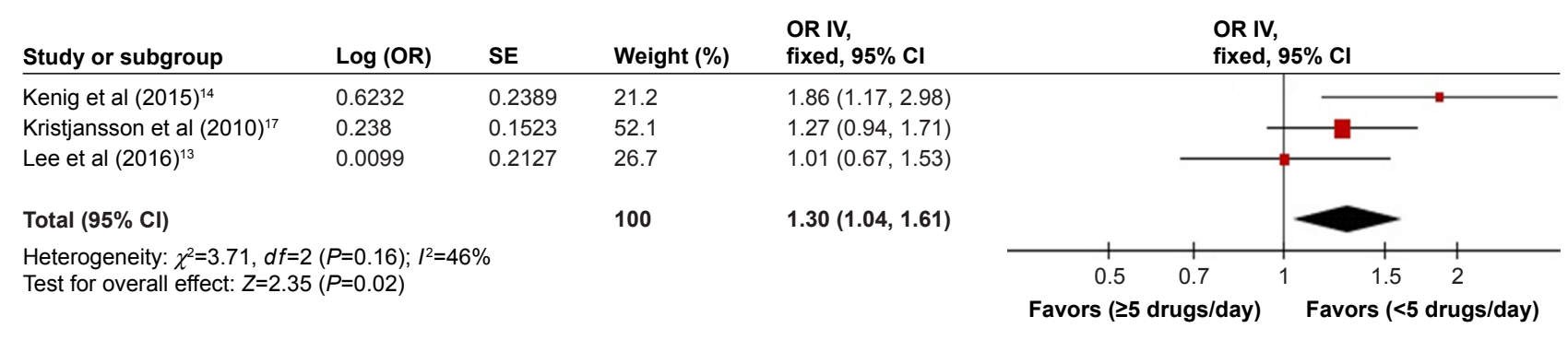

Figure 3 Effects of polypharmacy on 30-day postoperative major complications. Abbreviations: OR, odds ratio; SE, standard error; IV, inverse variance. 


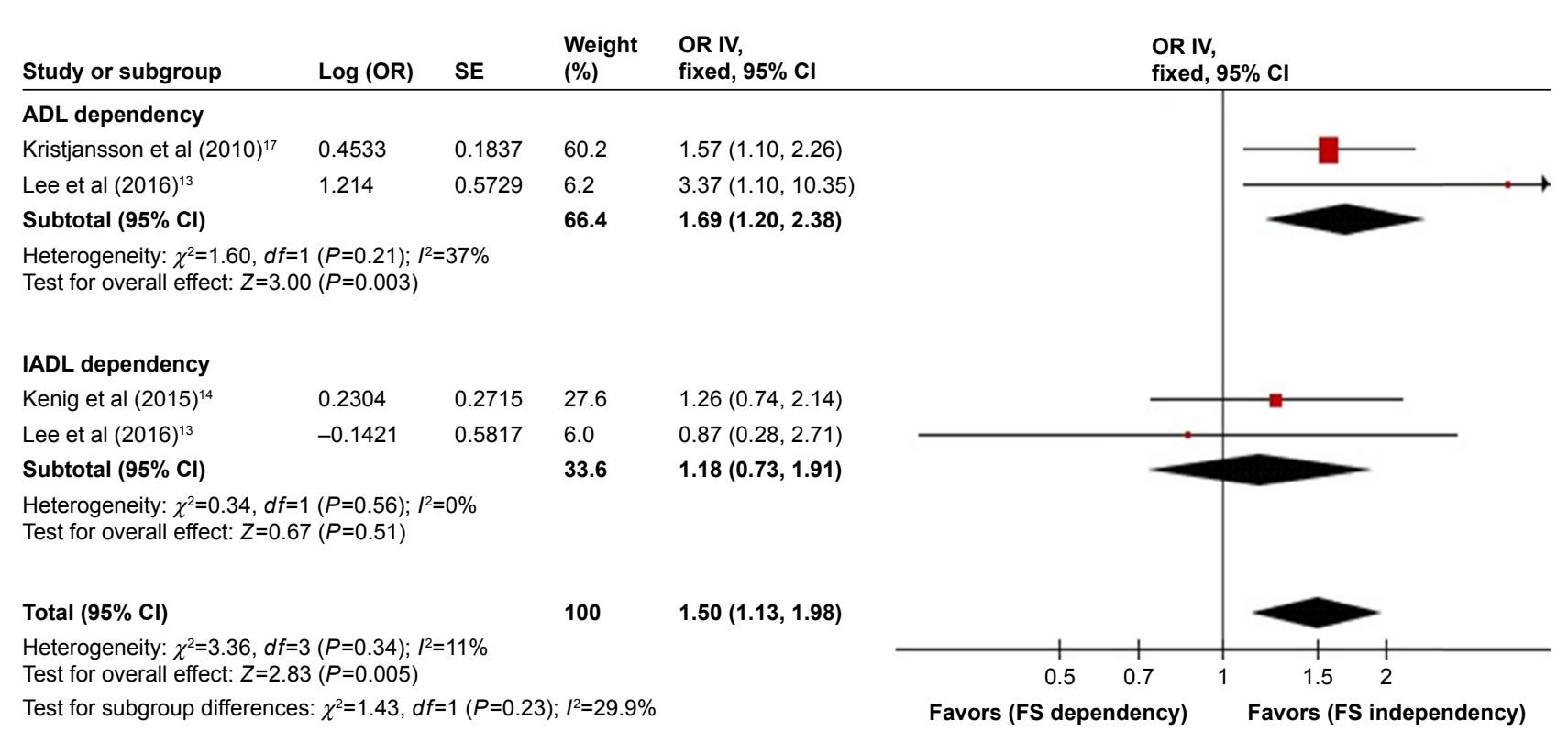

Figure 4 Effects of FS on 30-day postoperative major complications.

Abbreviations: FS, functional status; OR, odds ratio; SE, standard error; IV, inverse variance; ADL, activities of daily living; IADL, instrumental activities of daily living.

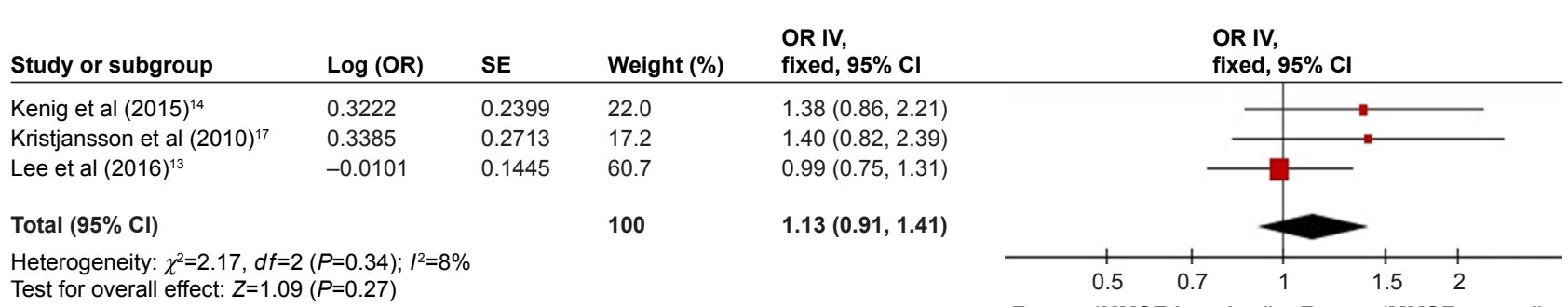

Test for overall effect: $Z=1.09(P=0.27)$

Favors (MMSE impaired) Favors (MMSE normal)

Figure 5 Effects of cognition on 30-day postoperative major complications.

Abbreviations: OR, odds ratio; SE, standard error; IV, inverse variance; MMSE, Mini-Mental State Examination.

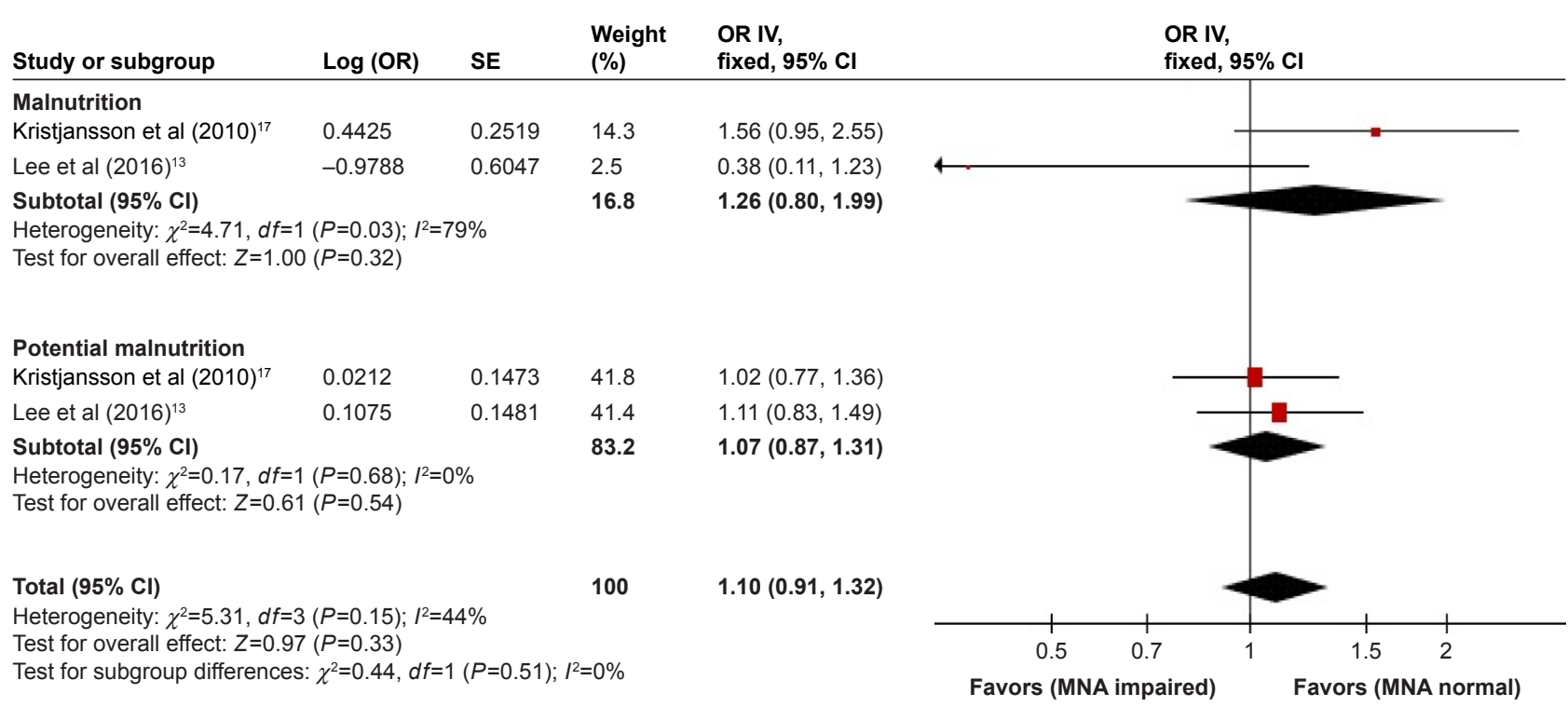

Figure 6 Effects of nutrition on 30-day postoperative major complications.

Abbreviations: OR, odds ratio; SE, standard error; IV, inverse variance; MNA, Mini Nutritional Assessment. 


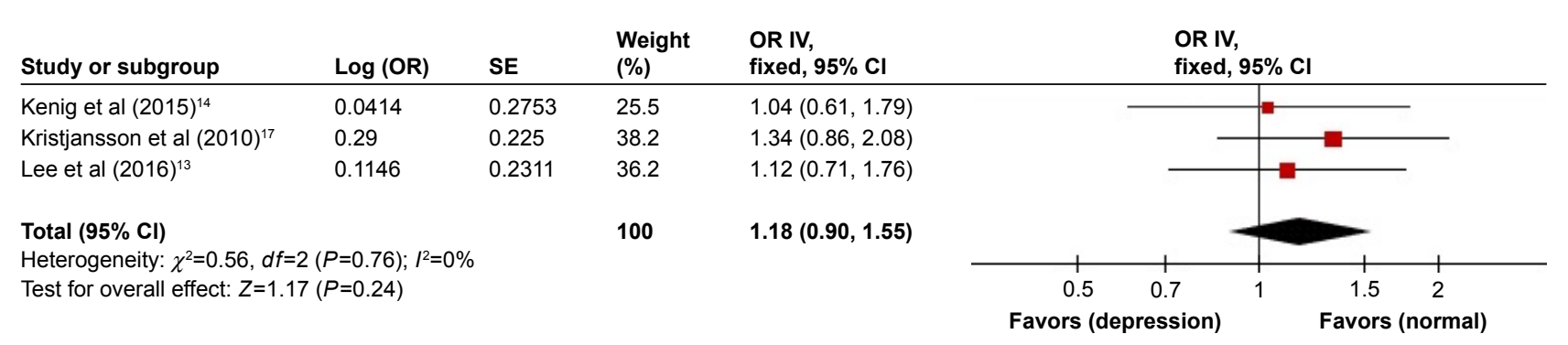

Figure 7 Effects of depression on 30-day postoperative major complications. Abbreviations: OR, odds ratio; SE, standard error; IV, inverse variance.

assessment, revealing that frailty was significantly associated with 30-day postoperative major complications. ${ }^{16}$ Tan et al ${ }^{18}$ used Fried criteria to evaluate frailty and showed that patients who were positive for the frailty syndrome have a significant four times higher risk of developing 30-day postoperative major complications.

\section{0-day postoperative major complications}

Ninety-day postoperative major complications were assessed in one study, and it demonstrated that polypharmacy, pain scale score $>0$ and $\geq 10 \%$ weight loss in the past half year were independently related to 90 -day postoperative major complications. ${ }^{19}$

\section{Discussion}

\section{Predictive value of components of CGA for postoperative complications \\ Comorbidity}

Comorbidities referred to underlying diseases (physical or mental) in patients, other than the disease under treatment. ${ }^{21}$ CCI was used to evaluate the severity of comorbidities, and this study showed that CCI $\geq 3$ was a predictor of 30-day postoperative major complications in gastrointestinal cancer patients. A study by Tan et $\mathrm{al}^{23}$ proved that CCI $\geq 5$ was an independent predictive factor of postoperative morbidity for octogenarians undergoing colorectal cancer surgery. Another study involving 204 patients with a median age of 84 years who had surgery for colorectal cancer showed that $\mathrm{CCI}>3$ can predict worse perioperative complications independently. ${ }^{22}$ Age-associated organ reserve decline, compounded by chronic diseases, has led to high incidence of postoperative complications in the elderly patients. ${ }^{24}$ The more the comorbidities and their seriousness, the higher the incidence of postoperative complications..$^{24}$

\section{Polypharmacy}

Polypharmacy broadly means use of a large number of medications and potentially unsuitable medications increasing the risk for adverse drug events, medication underuse and duplication. ${ }^{25}$ It was reported that geriatric patients are great consumers of medications (3.9 drugs/day for ages $65-80$ years, 4.4 drugs/day for ages $>80$ years) and the most common prescription drugs are cardiovascular medications (65\%), followed by those acting on the central nervous system. ${ }^{26}$ This study found that polypharmacy ( $\geq 5$ drugs/day) could predict postoperative major complications, which was consistent with the result of the study of Pujara et al. ${ }^{19}$ Elderly patients are more sensitive to the effects of drugs due to agerelated changes in pharmacodynamics and pharmacokinetics, and the greater the number of drugs, the more the side effects caused by them. ${ }^{26}$ Some medications such as anticholinergic drugs, meperidine and benzodiazepines would increase the risk of postoperative cognitive dysfunction, a common postoperative major complication. ${ }^{27}$

\section{FS}

FS focused on the patient's abilities to perform ADL. ${ }^{28}$ It can be assessed in numerous ways; ADL and IADL were used most frequently, and it was reported that the prevalence of $\mathrm{ADL}$ and IADL dependency for geriatric patients ranged from $7.5 \%$ to $51.4 \%$ and from $10.8 \%$ to $72.9 \%$, respectively. ${ }^{13,29,30}$ This study indicated that ADL dependency could predict 30-day postoperative major complications and the prediction of IADL dependency was inconclusive. Lee et a ${ }^{13}$ involved a multivariable analysis of the CGA domains and revealed that low ADL was significantly and independently associated with a risk of developing postoperative major complications. A recent study by Leavitt et $\mathrm{l}^{31}$ showed that ADL could predict complications following percutaneous nephrolithotomy. Patients with ADL deficiency may not have enough physiological reserve to endure and rehabilitate from a major surgery successfully. ${ }^{31}$ Kothari et al ${ }^{32}$ demonstrated in a prospective 
study enrolling patients $\geq 70$ years old scheduled for thoracic surgery that dependency with IADL "shopping" was a predictive factor for 30-day major complications. It was suggested that more prospective investigations of a minimal data set containing these parameters may be conducted to explore the prediction of IADL dependency for postoperative major complications in gastrointestinal cancer patients.

\section{Cognition}

Cognitive impairment is common in elderly patients, and studies showed that the prevalence ranged from $7 \%$ to $56 \% .{ }^{17,33}$ In this study, it was found that the prediction of MMSE cognitive impairment for 30-day postoperative major complications was inconclusive, which was similar to the research by Lee et al. ${ }^{13}$ However, Maekawa et $\mathrm{al}^{34}$ recently demonstrated in a retrospective study of 517 patients aged 75 years or older with gastrointestinal cancer surgery that MMSE was an independent factor related to the incidence of postoperative delirium after adjusting traditional risk factors. Multiple logistic regression analysis was performed in the research of Zhang et $\mathrm{al}^{24}$ and showed that cognitive function evaluated by Short Portable Mental Status Questionnaire (SPMSQ) was an independent influencing factor for postoperative complications. Explanations may be that patients with impaired cognition were less likely to engage in postoperative aggressive pulmonary toilet and ambulation, causing a high risk of developing postoperative complications such as pneumonia, deep vein thrombosis, stroke and cerebrovascular accident with neurologic deficit. ${ }^{35}$ Different results might exist because of different diagnostic accuracies of cognitive evaluation tools, and investigations using high sensitivity and diagnostic accuracy of instruments need to be carried out.

\section{Nutrition}

Nutritional status is frequently impaired in geriatric patients with cancer due to reduced appetite, dental diseases and tumor-induced changes in metabolism, especially those with gastrointestinal cancer, with the reported high prevalence of up to $45.6 \%{ }^{36,37}$ This study did not show that malnutrition or potential malnutrition based on MNA could predict 30-day postoperative major complications in gastrointestinal cancer patients. However, one prospective study found that malnourished patients assessed by Subjective Global Assessment (SGA) were at risk for increased postoperative morbidity undergoing elective resection of colorectal cancer. ${ }^{38}$ A research from Mohri et al ${ }^{39}$ using Prognostic Nutritional Index (PNI) to evaluate nutrition revealed that preoperative PNI was a useful predictor for postoperative complications in patients with colorectal cancer. A number of assessment tools exist to identify malnutrition in patients with colorectal cancer, but different tools have different diagnostic accuracies and lack a standardized method. ${ }^{40,41}$ Therefore, it was recommended that a high-accuracy diagnostic test of nutritional tools based on evidence should be used to further determine the predictive value of nutritional status for postoperative complications.

\section{Depression}

Senility alone is a high risk factor for depression, and the preoperative psychological burden that patients likely suffer (eg, fear and concerns about the disease, outcome of the operation and postoperative complications) may complicate the situation; it was well known that the prevalence of depression for elderly oncological patients ranged from $11 \%$ to $44.5 \%$. $^{17,30,42}$ This study found that the prediction of GDS depression for 30-day postoperative major complications was inconclusive, similar to the research from Lee et al. ${ }^{13}$ However, a retrospective study enrolling patients $>75$ years of age with colorectal cancer surgery revealed that GDS was an independent factor of postoperative delirium. ${ }^{6}$ Kothari et $\mathrm{al}^{32}$ proposed that answering "yes" to GDS question 2 "Have you dropped many of your activities and interests?" was able to predict the incidence of major complications for patients with thoracic cancer. Findings from studies provided mixed results, and more prospective investigations of a minimal data set containing these parameters may be required to explore the prediction of depression for postoperative major complications in gastrointestinal cancer patients.

\section{Frailty}

Two of the included studies showed that frailty was a predictive factor of postoperative complications in elderly gastrointestinal cancer patients. Recently, a research from Petrakis et $\mathrm{al}^{43}$ used CGA to measure preoperative frailty and found that severe complications were more likely to happen in the frailty group of patients with colorectal cancer. Kristjansson et $\mathrm{al}^{44}$ demonstrated that surgeon's clinical judgment of frailty based on CGA predicted severe complications after elective colorectal surgery. These studies confirmed the potential benefits of evaluating frailty; it was indispensable to identify frailty patients prior to surgery, and so proper risk/benefit assessment can be performed. ${ }^{45,46}$

\section{Preoperative CGA for geriatric patients with gastrointestinal cancer undergoing surgery}

This meta-analysis set out with the aim of identifying the effectiveness of CGA for predicting postoperative complications in gastrointestinal cancer patients and showed that 
comorbidity ( $\mathrm{CCI} \geq 3$ ), polypharmacy ( $\geq 5$ drugs/day) and ADL dependency were valid predictive factors; the results of other geriatric instruments were not conclusive. It implies that comorbidity, polypharmacy and FS should be evaluated routinely for geriatric patients undergoing surgery. ADL was suggested to assess FS, evaluating home safety and fall risks and ordering physical therapy (PT) and occupational therapy (OT) to address impairments. Reviewing and documenting the complete medication lists to monitor for polypharmacy, discontinuing or substituting medications potentially unsuitable or reducing doses thus optimized preoperative status of geriatric patients. ${ }^{11,12,47}$

The American College of Surgeons National Surgical Quality Improvement Program (ACS NSQIP) and the American Geriatrics Society (AGS) published guidelines focusing on optimal preoperative assessment of the geriatric surgical patients, including multiple components of CGA such as cognition (Mini-Cog), depression (Patient Health Questionnaire-2), FS (ADL and IADL) and nutrition. ${ }^{48}$ An expert advice lately developed by the Chinese Medical Association of Geriatrics and the Department of Geriatrics of People's Liberation Army General Hospital recommended to use MMSE, ADL and GDS to assess elderly patients undergoing surgery ${ }^{48} \mathrm{~A}$ panel from the International Society of Geriatric Oncology (SIOG) proposed that domains including FS, cognition, mental health status, nutrition and geriatric syndromes should be evaluated using CGA and tools be available for implementation of CGA, but they could not endorse one instrument over another. ${ }^{12}$ More definitive studies are required to investigate the predictive value of instruments of CGA for predicting postoperative complications and standardizing assessment tools.

CGA is a multidimensional evaluation that involves patient's physical, mental and social well-being. ${ }^{10}$ Preoperative CGA could be helpful to identify existing or potential health problems, determine risk stratification, make decisions and implement goal-directed geriatric interventions in response to CGA deficits, thus optimizing preoperative status of elderly surgical patients and promoting perioperative care. ${ }^{11,12,47}$ Although CGA has extensively been studied and proposed as part of routine preoperative care among geriatric surgical oncology population, utilization of preoperative CGA remains limited. ${ }^{11,49} \mathrm{~A}$ recent survey showed only $6.4 \%$ of surgeons use CGA in their routine practice and only a minority of them screen for frailty. ${ }^{5}$

One reason may be that some screening tools of CGA are lengthy, making them impractical in a high-volume surgical practice. ${ }^{32}$ What is more, it was likely because geriatric management interventions have not been robustly studied in cancer population. ${ }^{11}$ Further studies may be required to develop and validate novel, short assessment tools for predicting postoperative complications and execute clinical trials investigating the impact of geriatric management interventions on outcomes in geriatric patients following cancer surgery.

\section{Limitations}

There are some limitations of this review. Fewer studies were included into this meta-analysis. Only four of the six studies were adjusted for possible risk factors such as age, sex and operative time; the adjustment factors in each study may be different, and other studies did not mention the adjustment. In addition, because different evaluation tools for each element of CGA were used in different studies, so there may exist heterogeneity among the studies. Subgroup analysis was conducted for some elements of CGA or only descriptive analysis. It was recommended that future studies should apply evidence-based assessment tools with a high diagnostic accuracy to further explore the predictive value of CGA for postoperative complications in elderly patients with gastrointestinal cancer surgery.

\section{Conclusion}

This meta-analysis showed that comorbidity (CCI $\geq 3$ ), polypharmacy ( $\geq 5$ drugs/day) and ADL dependency were predictive factors for postoperative complications in gastrointestinal cancer patients; the results of other geriatric instruments were not conclusive, pointing to insufficient studies and requirement of original investigations.

\section{Acknowledgment}

This work was supported by the Science and Technology Commission of Shanghai Municipality (grant number 16411951200).

\section{Disclosure}

The authors report no conflicts of interest in this work.

\section{References}

1. International Agency for Research, WHO. GOLBOCAN2012: Estimated Cancer Incidence, Mortality and Prevalence Worldwide in 2012. [EB/ $O L]$. 2017. Available from: http://globocan.iarc.fr/Pages/fact_sheets_ cancer.aspx.

2. Siegel RL, Miller KD, Jemal A. Cancer statistics. CA Cancer J Clin 2017;67:7-30.

3. Feng YJ, Wang N, Fang LW, et al. Burden of disease of colorectal cancer in the Chinese population, in 1990 and 2013. Chin J Epidemiol. 2016;37(6):768-772.

4. Wang BH, Wang N, Feng YJ, et al. Disease burden of stomach cancer in the Chinese population, in 1990 and 2013. Chin J Epidemiol. 2016, 37(6):763-767. 
5. Ghignone F, van Leeuwen BL, Montroni I, et al. The assessment and management of older cancer patients: a SIOG surgical task force survey on surgeons' attitudes. Eur J Surg Oncol. 2015;42(2):297-302.

6. Mokutani Y, Mizushima T, Yamasaki M, Rakugi H, Doki Y, Mori M. Prediction of postoperative complications following elective surgery in elderly patients with colorectal cancer using the comprehensive geriatric assessment. Dig Surg. 2016;33(6):470.

7. Knittel JG, Wildes TS. Preoperative assessment of geriatric patients. Anesthesiol Clin. 2016;34(1):171-183.

8. Griffiths R, Beech F, Brown A, et al. Peri-operative care of the elderly 2014: association of anaesthetists of Great Britain and Ireland. Anaesthesia. 2014;69(suppl 1):S81-S98.

9. Caillet P, Laurent M, Bastujigarin S, et al. Optimal management of elderly cancer patients: usefulness of the Comprehensive Geriatric Assessment. Clin Interv Aging. 2014;9:1645-1660.

10. Song YT. Geriatric Comprehensive Assessment. 1st ed. Beijing: Peking Union Medical College; 2012.

11. Magnuson A, Allore H, Cohen HJ, et al. Geriatric assessment with management in cancer care: current evidence and potential mechanisms for future research. J Geriatr Oncol. 2016;7(4):242.

12. Wildiers H, Heeren P, Puts M, et al. International Society of Geriatric Oncology consensus on geriatric assessment in older patients with cancer. J Clin Oncol. 2014;32(24):2595-2603.

13. Lee YH, Oh HK, Kim DW, et al. Use of a comprehensive geriatric assessment to predict short-term postoperative outcome in elderly patients with colorectal cancer. Ann Coloproctol. 2016;32(5):161-169.

14. Kenig J, Olszewska U, Zychiewicz B, Barczynski M, Mituś-Kenig M. Cumulative deficit model of geriatric assessment to predict the postoperative outcomes of older patients with solid abdominal cancer. J Geriatr Oncol. 2015;6:370-379.

15. Stang A. Critical evaluation of the Newcastle-Ottawa scale for the assessment of the quality of nonrandomized studies in meta-analyses. Eur J Epidemiol. 2010;25(9):603-605.

16. Kristjansson SR, Nesbakken A, Jordhøy MS, et al. Comprehensive geriatric assessment can predict complications in elderly patients after elective surgery for colorectal cancer: a prospective observational cohort study. Crit Rev Oncol Hematol. 2010;76(3):208-217.

17. Kristjansson SR, Jordhøy MS, Nesbakken A, et al. Which elements of a comprehensive geriatric assessment (CGA) predict post-operative complications and early mortality after colorectal cancer surgery? J Geriatr Oncol. 2010;1(2):57-65.

18. Tan KY, Kawamura YJ, Tokomitsu A, Tang T. Assessment for frailty is useful for predicting morbidity in elderly patients undergoing colorectal cancer resection whose comorbidities are already optimized. Am J Surg. 2012;204(2):139-143.

19. Pujara D, Mansfield P, Ajani J, et al. Comprehensive geriatric assessment in patients with gastric and gastroesophageal adenocarcinoma undergoing gastrectomy. J Surg Oncol. 2015;112(8):883-887.

20. Clavien PA, Barkun J, de Oliveira ML, et al. The Clavien-Dindo classification of surgical complications: five-year experience. Ann Surg. 2009;250(2):187-196.

21. Taira N, Sawaki M, Takahashi M, Shimozuma K, Ohashi Y. Comprehensive geriatric assessment in elderly breast cancer patients. Breast Cancer. 2010;17(3):183-189.

22. Tan KK, Koh FH, Tan YY, Liu JZ, Sim R. Long-term outcome following surgery for colorectal cancers in octogenarians: a single institution's experience of 204 patients. J Gastrointest Surg. 2012;16(5): $1029-1036$.

23. Tan KY, Kawamura Y, Mizokami K, et al. Colorectal surgery in octogenarian patients-outcomes and predictors of morbidity. Int J Colorectal Dis. 2009;24(2):185-189.

24. Zhang X, Wang BH, Chen SP. Predictive efficacy of comprehensive geriatric assessment for postoperative adverse events in elderly patients during perioperative period. Chin Nurs Res. 2017;31(11):1305-1310.

25. Maggiore RJ, Gross CP, Hurria A. Polypharmacy in older adults with cancer. Oncologist. 2010;15(5):507-522.
26. Bettelli G. Preoperative evaluation in geriatric surgery: comorbidity, functional status and pharmacological history. Minerva Anestesiol. 2011;77(6):637-646.

27. Inouye SK, Robinson T, Blaum C, et al. American Geriatrics Society abstracted clinical practice guideline for postoperative delirium in older adults. J Am Geriatr Soc. 2015;63(1):142-150.

28. Tsiouris A, Horst HM, Paone G, Hodari A, Eichenhorn M, Rubinfeld I. Preoperative risk stratification for thoracic surgery using the American College of Surgeons National Surgical Quality Improvement Program data set: functional status predicts morbidity and mortality. J Surg Res. 2012;177(1):1-6.

29. Kenis C, Decoster L, Van PK, et al. Performance of two geriatric screening tools in older patients with cancer. J Clin Oncol. 2014;32(1): $19-26$.

30. Hoppe S, Rainfray M, Fonck M, et al. Functional decline in older patients with cancer receiving first-line chemotherapy. J Clin Oncol. 2013;31(31):3877-3882.

31. Leavitt DA, Motamedinia P, Moran S, et al. Can activities of daily living predict for complications following percutaneous nephrolithotomy? J Urol. 2015;195(6):1805-1809.

32. Kothari A, Phillips S, Bretl T, Block K, Weigel T. Components of geriatric assessments predict thoracic surgery outcomes. J Surg Res. 2011; 166(1):5-13.

33. Smith NA, Yeow YY. Use of the Montreal Cognitive Assessment test to investigate the prevalence of mild cognitive impairment in the elderly elective surgical population. Anaesth Intensive Care. 2016;44(5): 581-586.

34. Maekawa Y, Sugimoto K, Yamasaki M, et al. Comprehensive Geriatric Assessment is a useful predictive tool for postoperative delirium after gastrointestinal surgery in old-old adults. Geriatr Gerontol Int. 2016; 16(9):1036-1042.

35. Gajdos C, Kile D, Hawn MT, Finlayson E, Henderson WG, Robinson TN. The significance of preoperative impaired sensorium on surgical outcomes in nonemergent general surgical operations. JAMA Surg. 2014; 150(1):30-36.

36. Wu B, Yin TT, Cao W, et al. Validation of the Chinese version of the Subjective Global Assessment scale of nutritional status in a sample of patients with gastrointestinal cancer. Int J Nurs Stud. 2010;47(3): 323-331.

37. Kim S, Brooks AK, Groban L. Preoperative assessment of the older surgical patient: honing in on geriatric syndromes. Clin Interv Aging. 2015;10:13-27.

38. Lohsiriwat $\mathrm{V}$. The influence of preoperative nutritional status on the outcomes of an enhanced recovery after surgery (ERAS) programme for colorectal cancer surgery. Tech Coloproctol. 2014;18(11): 1075-1080.

39. Mohri Y, Inoue Y, Tanaka K, et al. Prognostic nutritional index predicts postoperative outcome in colorectal cancer. World J Surg. 2013; 37(11):2688-2692.

40. Håkonsen SJ, Pedersen PU, Bath-Hextall F, Kirkpatrick P. Diagnostic test accuracy of nutritional tools used to identify undernutrition in patients with colorectal cancer: a systematic review. JBI Database System Rev Implement Rep. 2015;13(4):141-187.

41. Liu X, Xu P, Qiu H, et al. Preoperative nutritional deficiency is a useful predictor of postoperative outcome in patients undergoing curative resection for gastric cancer. Transl Oncol. 2016;9(6):482-488.

42. Liu YP, Zhang J. Research progress on depression of colorectal cancer patients and its influencing factors. Chin Nurs Res. 2014;28(7): 774-777.

43. Petrakis IE, Andreou AG, Venianaki MV, et al. P460: outcome following colorectal surgery in elderly patients: our experience using the preoperative comprehensive geriatric assessment. Eur Geriatr Med. 2014; 5(suppl 1):S227-S228.

44. Kristjansson SR, Jordhoy MS, Nesbakken A, et al. Are surgeons able to identify frailty status pre-operatively in older patients with colorectal cancer? Eur Geriatr Med. 2013;4(suppl 1):S95. 
45. Isharwal S, Johanning JM, Dwyer JG, Schimid KK, LaGrange CA. Preoperative frailty predicts postoperative complications and mortality in urology patients. World J Urol. 2017;35(1):21-26.

46. Revenig LM, Canter DJ, Master VA, et al. A prospective study examining the association between preoperative frailty and postoperative complications in patients undergoing minimally invasive surgery. J Endourol. 2014;28(4):476-480.

47. Chow WB, Rosenthal RA, Merkow RP, et al. Optimal preoperative assessment of the geriatric surgical patient: a best practices guideline from the American College of Surgeons National Surgical Quality Improvement Program and the American Geriatrics Society. J Am Coll Surg. 2012;215(4):453-466.
48. Chinese Medical Association of Geriatrics, Department of Geriatrics of People's Liberation Army General Hospital. The expert advice of preoperative assessment for geriatric patients. Chin J Geriatr. 2015;34(11): 1273-1280.

49. Feng MA, McMillan DT, Crowell K, Muss H, Nielsen ME, Smith AB. Geriatric assessment in surgical oncology: a systematic review. J Surg Res. 2015;193(1):265-272. 


\section{Supplementary materials Search strategy used \\ PubMed}

((Stomach neoplasms OR colorectal neoplasms OR rectal neoplasms [MESH Terms]) OR (gastrointestinal neoplasms [Text Word])) AND (Comprehensive geriatric assessment [Text Word] OR CGA [Text Word] OR geriatric assessment [Text Word]).

\section{Embase}

(Stomach OR gastric OR colon OR rectal OR colorectal OR gastrointestinal).mp. AND (Neoplasms OR cancer OR carcinoma OR tumor).mp. AND (comprehensive geriatric assessment OR CGA OR geriatric assessment).mp.

\section{Publish your work in this journal}

Clinical Interventions in Aging is an international, peer-reviewed journal focusing on evidence-based reports on the value or lack thereof of treatments intended to prevent or delay the onset of maladaptive correlates of aging in human beings. This journal is indexed on PubMed Central, MedLine,
CAS, Scopus and the Elsevier Bibliographic databases. The manuscript management system is completely online and includes a very quick and fair peer-review system, which is all easy to use. Visit http://www.dovepress. com/testimonials.php to read real quotes from published authors. 